\title{
RITUAIS DO PODER NAS ORGANIZAÇÕES DE SAÚDE
}

Sirlene Aparecida Pessalacia Barreto ${ }^{1}$

Iris Fenner Bertani ${ }^{2}$

\section{RESUMO}

O poder é ambicionado pelo ser humano que o deseja ter para si; já que através dele se sente equiparado a uma divindade capaz de tudo dominar. Quando mais frágil se encontra estruturada a personalidade do sujeito, mais necessita de poder para camuflar sua impotência. As organizações sempre foram lugares de exercício de poder. Nas organizações clássicas o poder se confunde com o pai-trão ou com os chefes. Nas organizações hipermodernas o poder se despersonaliza, passando as relações passionais a serem vivenciadas através das estruturas e valores nelas cultivados. Nas organizações de saúde, o poder se concentra no médico, pelo consentimento implícito da sociedade, tornando rígida a construção da sua identidade profissional. Os rituais são desenvolvidos e adotados nas instituições como forma de perpetuar o poder instituído. Há uma identificação dos trabalhadores com a imagem projetada da organização, surgindo um campo fértil para se implantar ideologias e políticas que são culturalmente introjetadas como verdadeiras.

PALAVRAS-CHAVE: Organização; Poder; Trabalho; Saúde; Hospital.

\section{INTRODUÇÃO}

A questão do poder é um assunto atual, mas que há muito vem sendo discutido por diversos autores e em diferentes áreas do conhecimento.

O poder assume uma grande importância no plano teórico e prático pois, situa-se nas várias correntes das ciências humanas e sociais - está infiltrado em todos os lugares e em todos os momentos de nossas vidas.

O poder é retratado não somente através de grupos sociais, mas também pelas grandes organizações representando um sistema econômico, político, social, ideológico e

\footnotetext{
${ }^{1}$ Psicóloga Clínica; Mestre em Serviço Social. Coordenadora de Equipe do QUAVISSS.

${ }^{2}$ Docente do Programa de Pós-Graduação em Serviço Social - FHDSS - UNESP / Franca. Líder do QUAVISSS.
}

\begin{tabular}{llllll}
\hline Serviço Social \& Saúde & Campinas & v. 4 & n. 4 & p. 1-156 & Maio 2005
\end{tabular} 
psicológico. Aqui enfatizamos o poder nas organizações tanto nas clássicas como nas hipermodernas - multinacionais. As empresas modernas atuam como mediadoras de conflitos dos trabalhadores, funcionando de forma coerciva mais ou menos subliminar, mas também dando privilégios, incentivo nas questões de crescimento profissional, qualidade de vida, orientação no cuidado com os filhos, preparo para a aposentadoria etc, o que facilita às pessoas individualizadas suportarem grandes cargas de tensão no trabalho. São, portanto, as organizações agentes estruturantes do imaginário dos indivíduos se consolidando como ideal de ego - objeto de identificação e de amor, fonte de prazer mas, também de angústia e dependência.

O poder se globaliza e toma formas diversificadas, trazendo ao cotidiano das pessoas que dele fazem uso em seu próprio benefício cada vez mais satisfação, e por outro lado, levando pessoas a sofrerem sem distinguir claramente qual é o mal que as afetam.

\section{PARA DEFINIR E ENTENDER O QUE É PODER}

Definir o que é poder é um desafio, visto que permanece indeterminado, difícil de ser estabelecido com precisão - é amplo, não podendo ser esclarecido com exatidão o que a palavra designa.

O poder não se detém como uma coisa, como uma propriedade que se possui ou não - o poder não existe, o que existe são práticas ou relações de poder. É algo que se exerce, que se efetua - não é um objeto, uma coisa, mas uma relação.

Há uma infinidade de situações que podemos aplicar a palavra “poder” - poder do Estado; poder do patrão; poder da justiça, poder de Deus; poder do sobrenatural; os três poderes e assim em muitas outras situações.

Max Weber (1978) define poder como: “[...] a probabilidade de impor a própria vontade dentro de uma relação social, ainda contra toda resistência e qualquer que seja o fundamento desta probabilidade.”

O poder é um fenômeno que nos inspira força, coação e coerção tanto físicas, econômicas como psicológicas, podendo ele se basear tanto na força como na crença de “ter” que obedecer. É sempre uma prática social e bilateral construída historicamente, 
relação entre dois ou mais agentes - sendo concebida no âmbito social que para existir necessita de vontades submetidas - é uma relação cujos elementos materiais não são suficientes para defini-lo, sua legitimidade é obtida com o consentimento daqueles que a ele se submetem, passando a ser reconhecido.

Nada exerce mais atração sobre os seres humanos do que o poder - legado dado aos seres divinos, o que fascina e deslumbra o homem - há uma estreita relação entre a divindade e o detentor do poder.

O poder seduz na medida que é capacidade de impor e de transformar a realidade - confere ação e mobilidade. Aquele que detém o poder sente que pode traçar seu próprio destino e o destino dos dominados; gera ilusões de invencibilidade e potência, aproximando os homens dos Deuses.

Os seres mortais, segundo a mitologia, sempre invejaram os Deuses pelos seus poderes, almejaram na eternidade ser um deles - o poder traz a falsa condição de sentir-se Deus, de tudo poder, camuflando personalidades frágeis, incompletas. Quanto mais frágil a personalidade, mais ela necessita de poder. É nessa medida que o poder corrompe - o seu detentor se coloca na posição de uma divindade, assim passando a se posicionar; torna-se capaz de morrer ou matar. A história, a literatura e mesmo o cinema nos mostram personagens reais ou fictícios que representam o fenômeno do poder desvairado, sem medida, que pode ser definido como “doentio”.

Muitos pensadores como Maquiavel, Montesquieu, Locke, Nietzsche, Bakhtin, e Foucault entre outros, se ocuparam da questão do poder - suas características, suas formas de obtê-lo, mantê-lo e desvendá-lo, e mesmo, questionar metodologicamente a legitimidade desse discurso.

O poder está na rua, nas bancas de jornal, nas revistas, na T.V, enfim no dia-a-dia em qualquer lugar do mundo - vemos todos os dias na política partidos que disputam controle, seja no Legislativo ou no Executivo; lobby; medidas provisórias são temas que se tornaram comuns nas rodas de amigos e nas conversas.

O poder é uma das maiores aspirações do ser humano, tem suas raízes há milhões de anos atrás, quando as forças dividiam nossos ancestrais em líderes e liderados. Quando o 
homem superou sua condição de sobrevivência da espécie e ingressou na história como ser capaz de mudar seu modo de viver, já trazia dentro de si o instinto do poder.

O poder surge da necessidade de se organizar em sociedade, de ordenar e buscar um bem comum, como forma de viabilizar a existência do homem na terra. Não existe forma de organização social animal ou humana que não tenha os que mandam e os que obedecem - nem que seja através de uma certa alternância - o poder vem da própria organização da vida em comunidade; ou, no caso do homem, da convivência em sociedade.

A organização do homem em clãs, grupos e sociedades tornaram mais clara essa necessidade. A vida em sociedade é uma permanente luta pelo poder - grupos sociais tomam defesa de seus interesses ideológicos que muitas vezes são conflitantes e motivo de disputa de poder.

Na sociedade contemporânea, a luta pelo poder está em casa, no bairro, nas empresas e em cada grupo social. A partir do momento em que se insere numa sociedade já se é protagonista ou coadjuvante do instigante jogo do poder.

A primeira forma de organização social é a família. No limite, como observa Reich (1974, p. 32), a família é o modelo reduzido do Estado autoritário, ou seja: “[...] o seu objetivo é fabricar um cidadão que se adapte à ordem assente na propriedade privada, que a tolere apesar das misérias e humilhações. Como etapa prévia nessa via, a criança passa pelo estado autoritário em miniatura, a criança tem que começar por adaptar-se se mais tarde quiser poder inserir-se no quadro geral da sociedade”. Passados 30 anos desta reflexão, a dinâmica social trouxe novas configurações que a família vem apresentando, embora a questão do poder ainda lhe é inerente. Atualmente, muitas situações colocam em discussão as afirmações de Reich, já que a nova "sociedade do espetáculo" cada vez mais induz a construção de personalidades narcisistas. Exige a "fabricação" do indivíduo vencedor, incapaz de ouvir e pronto para mandar, ressaltando mais e mais o papel social da apropriação do poder que resulta em sucesso material e relacional, ampliando inclusive as possibilidades de ser amado e respeitado simultaneamente, desejo vital dos seres humanos.

\begin{tabular}{llllll}
\hline Serviço Social \& Saúde & Campinas & v. 4 & n. 4 & p. 1-156 & Maio 2005
\end{tabular} 


\section{O PODER DAS ORGANIZAÇÕES}

Entendemos por organizações o que se refere a uma realidade social como: uma fábrica, uma empresa, um hospital, um banco, uma escola - são instituições estabelecidas com objetivos definidos, seja a produção, distribuição de bens, prestação de serviços, proteção do patrimônio, formação de homens, entre outros.

Toda organização é dinâmica e nesse movimento transforma continuamente todo um conjunto de valores, ideologias, respostas e contradições; podendo evitar ou ainda acentuar conflitos, na maioria das vezes produzidos e sustentados pela mesma.

PAGÉS (1993), faz uma análise entre organizações clássicas que são empresas menores, nacionais com uma hierarquia bem definida e conhecida; e as hipermodernas (multinacionais) que não são mais representadas pela figura do patrão ou chefes mas, por macroestruturas, sendo todos os funcionários referidos como “colaboradores", “associados”, que se encaixam numa superengrenagem. Estas macroestruturas utilizam-se de políticas diversas, como a mediação que é prática de políticas contraditórias, aliando restrições às vantagens oferecidas aos seus empregados.

Através da mediação a organização administra conflitos, antecipando-os, absorvendo-os e transformando-os antes de se tornarem conflitos coletivos.

O processo de mediação exerce a atividade das contradições; faz uma aliança com as restrições (coações) da empresa e com os privilégios que a mesma oferece aos seus trabalhadores. Trabalha dentro de um sistema contraditório desenvolvendo as forças produtivas desses profissionais como: a iniciativa, a atividade intelectual, a capacidade de criação, a cooperação dando a eles toda espécie de satisfação de ordem econômica, política, ideológica, psicológica, bons salários, trabalho interessante, prazer, mas, ao mesmo tempo garante o seu poder subordinando essas forças produtivas aos objetivos da empresa e ao sistema capitalista - o trabalhador acredita que pode e tem tudo que deseja, desde que tudo que deseja seja o desejo e o interesse da organização - os privilégios são oferecidos a seu modo, reforçando a dependência dos mesmos e destituindo-os do poder de se organizarem e saírem dos domínios da empresa.

As diretrizes administrativas introduzidas atualmente pela Human Resources Management (HRM) refletem em parte esse tipo de organização hipermoderna, onde o 
cultivo de forte cultura interna fornece o estímulo da equipe, do engajamento na 'missão' e do 'foco' no empreendimento. (SPINK, 1994). O embasamento proposto pela HMR apresenta metas institucionais voltadas para o alto grau de comprometimento, altos índices de respostas produtivas, foco na qualidade, flexibilidade na mão-de-obra e integração estratégica. Nesta mesma linha de raciocínio, Spink (1994) lembra ainda que o trabalhador, não precisa olhar além da organização para seu sustento emocional e intelectual.

A organização nesse sistema está representando o ideal historicamente construído da personalidade do indivíduo, passando o mesmo a trabalhar para a organização como se esta fosse dele - acreditando que a organização faz parte de si, uma extensão de sua família, da mesma forma que ele faz parte da organização. Esquece que é empregado assalariado e que não partilha dos resultados financeiros da Empresa - Mãe. Participa, isso sim, "apenas" do esforço de erguê-la e fazê-la render, sentindo satisfação nessa identificação orgulhando-se de aliar ao seu nome, o "sobrenome” da Empresa.

Este processo encontra suas raízes também no inconsciente das pessoas, oferecendo um sistema de crenças, ideologias, respondendo não só às necessidades criadas pela relação com o mundo, mas também às necessidades interiores do indivíduo. Partindo dessa idéia o indivíduo procura se adaptar ao modelo originado pela organização, encontrando aí os desafios cuja superação lhe proporcionam uma fonte de satisfação e valorização narcisista, o que justifica a aceitação das restrições e da carga que o trabalho lhe suscita - quanto maior for a satisfação, mais aceitação se tem e quanto mais poderosa for a organização, maior a satisfação dos que com ela se identificam. Satisfação e insatisfação ao falar do trabalho, não são opostos, mas um contínuo que lentamente vai-se alternando e transformando.

Há um processo de introjeção e de identificação, o indivíduo ama a organização pela sua aceitação na sociedade, quanto maior o prestígio institucional, maior é seu sentimento, porque almeja para si esta condição de "perfeição" - as qualidades da organização passam a ser suas qualidades - surge uma fusão entre indivíduo e organização, despersonalizando o trabalhador enquanto coletividade.

Estes tipos de organizações utilizam-se dos ideais da sociedade global influenciando famílias, escolas e pessoas, investindo em abstrações sobre comportamentos

\begin{tabular}{llllll}
\hline Serviço Social \& Saúde & Campinas & v. 4 & n. 4 & p. 1-156 & Maio 2005 \\
\hline
\end{tabular}


de autoconstrução, chamando o trabalhador a demonstrar seu compromisso e energia positiva para o trabalho, tornando-as, enfim, um lugar de produção de conformismos.

Há toda uma dominação absorvida a nível inconsciente que tem a capacidade de modelar comportamentos, atitudes e pensamentos dos indivíduos. A organização passa a funcionar como uma droga dando prazer e angústia; os indivíduos assumem as mesmas com suas regras e ideologias como sendo parte de si mesmos - não conseguindo separar-se e romper com este estado de coisas.

Nas organizações clássicas onde o dono é a pessoa detentora do poder, em alguns casos há uma confusão com a pessoa do pai-trão, que se admira mas, também se odeia como um pai e um Deus - passando as relações psicológicas passionais a se objetivarem nas pessoas mais próximas como os chefes. Isto porque o pai-trão é temido e adorado ao mesmo tempo; um exemplo a ser imitado, alguém com quem se deve ter cuidado - os sentimentos se projetando para o chefe como alguém mais próximo - mais humano.

Nas organizações ditas hipermodernas, estes sentimentos deixam de ser personalizados em um superior hierárquico, e se tornam impessoais. A dependência afetiva se desfoca e se instaura na própria organização - as emoções não encontram espaço para se alojarem nas pessoas, redirecionando-se para a própria estrutura institucional.

O trabalhador liberta-se da tutela do chefe ou mesmo de outras figuras significativas as quais ama, admira, odeia e se identifica ou sente repulsa; passando para uma tutela boa, idealizada, segura mas também obscura, impessoal, ameaçadora, pérfida, que toma conta de sua vida.

Há a troca do tipo paternal (pai-trão) para o maternal - a organização pode agora ser associada a uma figura inconsciente feminina - a mãe, que é o motor da dominação psicológica, que dá mas também retira o amor, causando um medo maior do que a coação ou a interdição do Pai como Lei. Há uma superação da ameaça constante da punição que o pai representa - "mata-se” o pai como em Totem e Tabu (FREUD, 1913) mas, paga-se caro por esta ousadia. A mãe acolhedora, que cuida nas horas aflitivas, que ajuda sempre que é chamada a socorrer, que nunca falta quando se precisa, começa a tomar parte da relação de trabalho, em substituição a figura do cidadão que trabalha e que é sujeito de direitos. Uma regressão vai-se instalando em suas vivências juntamente com a dependência constante em

\begin{tabular}{llllll}
\hline Serviço Social \& Saúde & Campinas & v. 4 & n. 4 & p. 1-156 & Maio 2005 \\
\hline
\end{tabular}


relação à organização-mãe - uma busca incessante do amor que essa mãe não satisfaz por completo e um medo terrível de perder o que nem mesmo chega a ter.

Nessas organizações, a manipulação psicológica do trabalhador “quebra-lhe a coluna dorsal” e cria-se uma situação de amor condicional - só se é amado com a condição de lhe dar em troca um amor submisso. Cada pessoa individualmente vive a ilusão que pode enfim ser amado plenamente, na condição de se submeter às exigências do objeto de amor.

Toda essa trama retira da pessoa a capacidade de elaboração a um nível mais consciente e de autodirecionamento de sua própria vida, dentro de parâmetros da visão crítica da questão social em que está inserido seu cotidiano. As trocas emocionais com a organização não se realizam no mundo real e permanecem no imaginário - o sujeito é levado a internalizar uma imagem rígida, porque o objeto que ele teme e deseja não existe de fato, é uma formação inconsciente de recompensas simbólicas que lhe possibilitam a sensação de segurança e respostas às suas necessidades.

Esta situação tende a causar um empobrecimento na identidade do indivíduo, ligada diretamente à sua atividade e às trocas que este faz com o meio do qual vive e depende material e psicologicamente, pois não tem condições de testar os limites da organização - processo este essencial para diferenciar-se do outro, para separar a fantasia da realidade.

\section{PODER NAS ORGANIZAÇÕES DE SAÚDE}

Nas organizações chamadas "médicas” ou “de saúde”, tais como hospitais e clínicas, que se caracterizam pelo internamento de pessoas para tratamento de doenças, o que pode envolver tanto cirurgias e todo o aspecto ameaçador de ser cortado e sofrer incisões mais ou menos profundas para a retirada de partes doentes, como para tratamento medicamentoso, em que as dosagens de drogas interferem nos ritmos biológicos e mentais.

As pessoas que se encontram nessa situação muitas vezes sentem-se fragilizadas pela dor e pelo medo. São momentos que devem enfrentar sozinhas, pois as agressões em nome da cura ocorrem em seu próprio corpo, por mais apoio que recebam de terceiros. É preciso que os doentes acreditem que estão recebendo o remédio certo que os irá curar, a

\begin{tabular}{llllll}
\hline Serviço Social \& Saúde & Campinas & v. 4 & n. 4 & p. 1-156 & Maio 2005 \\
\hline
\end{tabular}


cirurgia necessária que irá extirpar os males, para aceitar a internação e as interferências externas em suas vidas e em seus corpos. Atrás dessa crença, do melhor atendimento possível, mesmo em situações precárias, instala-se todo um ritual de poder e autoridade, que faz com que as dúvidas sejam afastadas e a "entrega” seja realizada. Nesta situação especial, outros profissionais não-médicos, mas com atividades “curadoras” a partir de conhecimentos desenvolvidos em diferentes áreas do saber, são tratados de modo inferiorizado, dentro da rígida hierarquia própria do ambiente hospitalar.

Muitos são os aspectos que encerram os rituais necessários a manutenção do poder institucional hospitalar como um lócus de indiscutível "reinado médico”. Outros profissionais neste espaço são considerados atores coadjuvantes, ou, como se diz nas representações de peças teatrais, “escadas”, para que o profissional dominante não fique vulnerabilizado, tendo suas ações questionadas e o desempenho de seu papel colocado em dúvida.

Tudo isso faz sentido ao corresponder com a necessidade do doente sentir-se protegido, cuidado, e que tudo terminará bem. Deixa-se a este profissional o direito de interferir e modificar a vida do doente, muito embora os prejuízos e danos que esta postura carregada de onipotência quase sem limites pode causar, estão sendo cada vez mais contestados.(KAISER, 2002.) Não há, contudo, qualquer lógica que escore o fato do alcance do bem-estar e ausência de dor não sejam aceitos como trabalho de um profissional capacitado, mas seja coberto por um clima de adoração, como se o profissional se transformasse no deus da cura e tivesse em suas mãos o poder do bem e do mal, da saúde e da doença. Assim é como ainda hoje alguns médicos menos preocupados com as relações humanas que estabelecem no seu dia-a-dia institucional, abrigando-se de forma corporativa e mantendo distância do "resto do mundo" hospitalar. Sabemos que atitudes defensivas demonstram medo e insegurança. (do fracasso, de "perder o paciente”, do erro, de não estar tão preparado como gostaria, de ser responsabilizado...)

A responsabilidade que historicamente o médico chamou para si, especialmente no panorama hospitalar, o impede de aceitar ser “fragilizado" por uma observação, um palpite, uma opinião discordante. Precisa ser dono da verdade para esconder de si mesmo seu próprio medo.

\begin{tabular}{llllll}
\hline Serviço Social \& Saúde & Campinas & v. 4 & n. 4 & p. 1-156 & Maio 2005
\end{tabular} 
O autoritarismo e as relações fortemente hierarquizadas dos hospitais altamente especializados encorajam os jovens médicos a adotarem identidades profissionais previamente definidas, perpetuando rígidas estruturas de pensar e agir. Seu papel deixa de ser construído processualmente na equipe e ao lado do cidadão - usuário de seus serviços; já está pronto he décadas para ser adotado - resta vesti-lo como a um jaleco branco.

A restrição identitária que adota ao assumir o papel dominante na equipe, resulta da elaboração de papéis sociais longamente tecidos na trama das relações culturais de nossa sociedade. Necessita o consentimento do restante da equipe que aceita e concorda em lhe delegar autoridade para resolver e decidir ações de cura, e mais do que isso, necessita do aval da sociedade que lhe entrega de olhos fechados os seus entes mais queridos para curar, salvar, tratar. Tão forte é essa identidade do médico com a cura que dele tudo se aceita: mensagens cifradas, linguagem inacessível, letra ilegível, medicação sem considerar os efeitos colaterais, ação e resultados não plenamente esclarecidos.

Esta postura ajuda a perpetuar o poder médico e enfraquece a cidadania do doente: ele precisa obedecer ao ser que tudo sabe como se ele mesmo ignorasse seus desejos, suas necessidades e sobre seu corpo. Torna-se objeto da intervenção médica com base no poder do conhecimento científico, que em nossos tempos assumiu um papel controlador das pessoas, que se rendem aos seus encantos e à sua mística.

Recentemente, graças à enorme popularização das notícias científicas, o enfoque no desenvolvimento da tecnologia tem ocupado cada vez mais espaço tanto na divulgação das conquistas objetivas conseguidas, como no imaginário das pessoas. Em lugar de desmistificar o papel do médico, a popularização das notícias científicas, tem servido para cada vez mais exigir altos níveis de performance especializada, afastando ainda mais o médico do "mundo dos mortais".

Isto porque o conhecimento leva a humanidade pela mão e o postulado de FOUCAULT, saber é poder, vem confirmar-se na reverência que o cotidiano começa a emprestar-lhe (1986, p. 18).

As decisões passam a pertencer ao cientista, ao conhecedor do possível, ao que ousar colocar a dúvida no real. A poucos é dada essa ousadia: de heróis passou a cientistas

\begin{tabular}{llllll}
\hline Serviço Social \& Saúde & Campinas & v. 4 & n. 4 & p. 1-156 & Maio 2005 \\
\hline
\end{tabular}


e destes, no campo da saúde, aos aplicadores da ciência médica, por ela instrumentados e dela emprestando a sua aura.

Assim é que ao ser humano comum, no seu cotidiano empresta à medicina toda sua esperança e devoção. A morte será enfim vencida pela manipulação genética e outros caminhos serão abertos a esse novo homem que virá sob encomenda, sem defeitos e sem doenças. Aos doentes graves, em nossa civilização, essa premissa se torna uma promessa. Os tratamentos se sofisticam e a mídia torna esse fato acessível a todos. Sabe-se que a ciência está resolvendo tudo e cada vez mais rapidamente, as barreiras do espaço e tempo rompidas pela aceleração do conhecimento, trazendo cura para todas as doenças. (BERTANI, 2002)

Alguém, em algum lugar descobrirá a cura das doenças e rapidamente seremos informados e tratados. O nosso modelo atual da morte, fala Ariès (1990), surgiu baseado na crença de que não há limite para o poder da técnica de transformar o homem e a natureza. O poder da cura, aliado à tecnologia de ponta e à mística salvacionista, é introjetado na vida das pessoas como um dos ícones do nosso tempo, trazendo para o cotidiano a idéia de felicidade possível.

Não são, contudo, os desejos de poder dos médicos que determinam a hierarquia das ações de saúde hospitalar: molda-se a Sociedade pelos seus próprios valores.

Ainda assim, desde os tempos bíblicos que fica claro que "os sãos não precisam de médico e sim os doentes” (Lucas 5: 31). É por isso que todo esse poder observado intramuros não se justifica quando a atenção à saúde fica voltada a aspectos preventivos das doenças, ações promocionais e de educação para saúde, enfocando mais as medidas de saúde pública como controle da água potável, destino dos dejetos, poluição atmosférica e outros fatores que poderiam apontar para soluções muito mais afetas a outros profissionais, já que escapam da esfera do individuo e suas dores, voltando-se a posturas de saúde ambiental e para grandes populações. Nesse espaço, que pode ser referido como o da sobrevivência da espécie sobre a terra, cada vez mais se observa uma diluição dos poderes tradicionais, embora o prestígio do médico se perpetue e se estenda também para esse domínio, tão solidamente se encontra culturalmente ancorado.

\begin{tabular}{llllll}
\hline Serviço Social \& Saúde & Campinas & v. 4 & n. 4 & p. 1-156 & Maio 2005
\end{tabular} 


\section{RITUAIS DE PODER}

Os rituais são formas de dizer coisas ou demonstrações de relações tanto sagradas como profanas - são instrumentos que permitem maior clareza às mensagens sociais (DA MATTA, 1983).

É através do ritual que a ideologia surge de forma explícita ou implícita nas relações estabelecidas dentro da organização.

Chamamos neste contexto de "rituais do poder", toda forma de controle, socialização e disciplina. Muitas organizações utilizam-se de programas de socialização preparando os indivíduos para ocupar um determinado cargo, ocorrendo um intenso processo de orientação de valores que o mesmo deverá internalizar, passando a desempenhar o papel indicado e executá-lo plenamente.

Essas estratégias de socialização têm como intuito “domesticar” os trabalhadores, principalmente aqueles que ocupam os níveis mais baixos da escala funcional da empresa.

As práticas disciplinares e ideológicas se iniciam dentro dos departamentos de recursos humanos, atualmente eufemisticamente chamados de departamentos de gestão de talentos. Seus procedimentos não são apenas formas descritivas do funcionamento da organização e de papéis profissionais; são também de transmissão de ideologias (crenças) e políticas (regras) institucionais.

Durante o processo de admissão, os indivíduos são submetidos a testes, entrevistas, dinâmicas de grupo, questionários, toda uma gama de procedimentos que vão permitir descrever, medir, classificar os candidatos e permitir objetivar as características de cada um, avaliar suas competências técnicas, sua capacidade de trabalho, suas motivações e reações frente a regras determinadas pela empresa e sua capacidade de integração. Dessa forma o candidato é submetido a um sistema que é uma forma de poder amparada por uma aparência científica desses procedimentos, eliminando a arbitrariedade e a subjetividade.

Podemos colocar também entre essas práticas, preconizações que incentivam a competição e a necessidade da superação dos próprios limites - é um exercício ideológico que valoriza e glorifica o sucesso individual superando seus próprios limites mas, que favorecem a um isolamento. O indivíduo aprende a obter prazer dominando o outro e a si mesmo, a serviço da organização.

Serviço Social \& Saúde Campinas

v. 4 n. 4 p. $1-156 \quad$ Maio 2005 
As organizações clássicas possuem uma estrutura hierárquica de extensão vertical e horizontal que multiplica os níveis de poder, suscitando em algumas pessoas (chefes) comportamentos (predispostos e/ou inconscientes) tiranos - são abusos de autoridade, menosprezo, falta de consideração, repreensões repetidas, ironias, afrontas gratuitas que levam o trabalhador a um descrédito do valor do seu trabalho e um desrespeito à sua competência.

Aqueles que, nas empresas, comportam-se como tiranos, freqüentemente recorrem a alguns mecanismos como: a negação do olhar, respostas dúbias, silêncios incompreensíveis, interrupções para atender demoradamente o telefone, conluios, atos e palavras não respeitados e demonstrações de temperamento que oscila entre o mau humor e o bom humor e o sorriso aberto: caprichos, cujo intuito é a afirmação de mando.

A linguagem é outro instrumento que pode tanto facilitar como dificultar relacionamentos e determinar posições. O falar é ao mesmo tempo objeto constitutivo do ser, descoberta de si mesmo, lugar de confronto de idéias e modo de influenciar pensamentos, atitudes e comportamentos.

As pessoas falam para serem ouvidas, respeitadas e também para exercer certa influencia no seu meio. Há indivíduos (chefes) que utilizam a palavra dando respostas tangenciais, procedimento sutil que nega a experiência do outro, causando comentários destes como: “ele não me ouve”; “ele só ouve aquilo que lhe interessa”; “ele me interrompe o tempo todo".

Já nas organizações hipermodernas, estes chefes são despersonalizados, perdendo sua importância; são substituídos em todos os níveis - por regras, políticas financeiras internas e outros dispositivos da empresa; e não mais nas suas decisões. Os investimentos e conflitos inconscientes e conscientes são vividos agora com a organização; assim, o poder se globaliza e imaterializa-se, há uma mudança do sistema do poder para uma abordagem mais global que visa a qualidade do produto através dos grupos de participação, colaboração contínua, envolvimento profissional-emocional. Novas formas de rituais formadas para garantir a colaboração incondicional do trabalhador - "colaborador", “associado” - para deixar o poder intocado e os lucros preservados nas mãos dos donos do capital.

\begin{tabular}{llllll}
\hline Serviço Social \& Saúde & Campinas & v. 4 & n. 4 & p. 1-156 & Maio 2005
\end{tabular} 


\section{CONSIDERAÇÕES FINAIS}

Podemos concluir que o poder institucional está em todo lugar, estendendo seu domínio muito além das relações de produção, da ordenação de espaços, da hierarquia, das normas. Partindo para o campo emocional, torna-se lugar de fácil manipulação dos indivíduos, no caso, os trabalhadores.

O poder é um sistema que não se inscreve numa pessoa ou num lugar - está nas relações que também se instauram na personalidade de cada um.

Os controles efetuados para a manutenção do poder são as restrições políticas, ideológicas, psicológicas que sempre existiram, sendo nova apenas a capacidade das empresas em introjetarem nas suas esferas privadas os ideais, valores, estilo de vida que se estruturam como desejos e necessidades no inconsciente das pessoas que nelas trabalham.

Hoje as formas de se exercer o poder vem deixando de ser imposição autocrática e se caracterizam por ser mais de ordem política, ideológica e psicológica - mecanismos sutis que se misturam ao que o indivíduo acredita ser obra de sua construção, num espaço que imagina seu.

As organizações hipermodernas são não só lugares de produção econômica, mas também de aprendizado político, prática de rituais e de crenças.

Este tipo de organização tem como característica a dominação psicológica que ela exerce sobre seus membros, possui uma capacidade de “construir” um indivíduo à sua própria imagem, capaz de reproduzi-la e fazê-la funcionar.

É um processo de reprodução social e cultural que Pagés (1993) chama de psicoideológico; há uma ação direta sobre o inconsciente das pessoas remodelando-o, reorganizando-o. As convicções pessoais divergentes enfraquecem progressivamente e o sujeito fica sob o jugo da organização, reforçando suas angústias, fantasias e diminuindo as possibilidades de real autonomia do indivíduo, despossuido de sua cidadania. As instituições médicas são ainda mais penalizadas em sua dinâmica, uma vez que o papel dominante do médico cria uma escala hierárquica onde ele ocupa o topo, credenciado pelos valores socialmente construídos na sociedade, e, mais que tudo, pelo papel que o

\begin{tabular}{llllll}
\hline Serviço Social \& Saúde & Campinas & v. 4 & n. 4 & p. 1-156 & Maio 2005
\end{tabular} 
conhecimento científico aliado ao pensamento mágico empresta ao papel deificado do médico na equipe de saúde e na vida dos doentes que atende.

Os trabalhadores das empresas modernas são mais alienados do que das empresas clássicas - mais enquadrados, mais satisfeitos com as recompensas materiais e simbólicas que a empresa oferece, mais insatisfeitos com seu preparo e rendimento profissional, pois são colocados num sistema que os encerra de todos os lados.

\section{ABSTRACT}

Power is ambitioned by human being who will it to himself (herself), because through it he (she) feels like a god, capable of dominate all. When a individual personality has a more fragile structure, the more he (she) needs power to hiden his (her) impotence. In the classic organizations, power is mixed with the concept of the father-owner or with the personification of the chief. In the hipermodern organizations, power is unpersonal, and the passional relationship is experienced on the institutional structure and in it cultivated values. In the health organizations, as the hospital, power is concentrated in the medicals doctors, by the implicited agreement of the Society, turning rigid the construction of their professional identity. The rituals are developed and adopted in the institutions as a way to perpetuate the institutionalized power. There are a identification of the workers with the projected image of the organization, arising a fertile field to implant ideologies and politics that are culturally accepted as true.

KEYWORDS: Organization; Power; Work; Health; Hospital.

\section{REFERÊNCIAS BIBLIOGRÁFICAS}

ARIÈS, Philippe. O homem diante da morte. Rio de Janeiro: F. Alves, 1990 (Coleção Ciências Sociais)

BERTANI, IRIS F. Filtrando a própria vida: estudo com jovens doentes renais em situação de hemodiálise. 2002. Tese (Livre Docência em Serviço Social) - FHDSS, UNESP, Franca.

\begin{tabular}{llllll}
\hline Serviço Social \& Saúde & Campinas & v. 4 & n. 4 & p. 1-156 & Maio 2005
\end{tabular} 
DA MATTA, Roberto. Carnavais, malandros e heróis: para uma sociologia do dilema brasileiro. 4. ed. Rio de Janeiro : Zahar, 1983.

FOUCAULT, Michel. Vigiar e punir: o nascimento da prisão. Petrópolis: Vozes, 1986.

FREUD, Sigmund. Totem e tabu. Edição Standard Brasileira das Obras Completas. Vol. XIII. Rio de Janeiro: Imago, 1969.

KAISER, Rachel. Fixing Identity by Denying Uniqueness: An Analysis of Professional Identity in Medicine. Journal of Medical Humanities. Sum 2; 23(2) 2002:95-105.

PAGÉS, Max et al. O poder das organizações. São Paulo: Atlas, 1993.

REICH, Wilhehm. Psicologia de massa do fascismo. Porto: Escorpião, 1974.

SPINK, P. Cidadania na organização e cidadania da organização: notas para a desconstrução de "recursos humanos” In: SPINK, M. J. P. (Org.) A cidadania em construção: uma reflexão interdisciplinar. São Paulo: Cortez, 1994.

WEBER, Max. Economia y sociedad. Bogotá : Fondo de Cultura Econômica, 1978. 